\title{
DEVELOPMENT AND EVALUATION OF COMMUNICATION-BASED MEASURES OF SITUATION AWARENESS
}

\section{CONTENTS}

Page

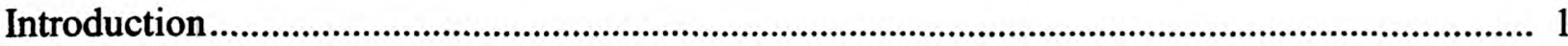

Development of Situation Awareness Measures .................................................................. 2

Radio Communications Checklist of Leader Awareness......................................................... 3

Future Expectations of Likely Leader Awareness .............................................................. 4

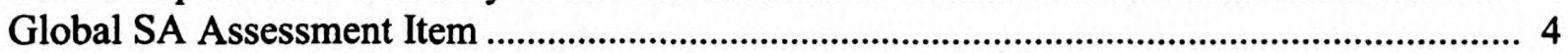

Evaluation of Situation Awareness Measures...................................................................... 4

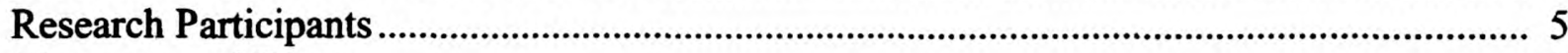

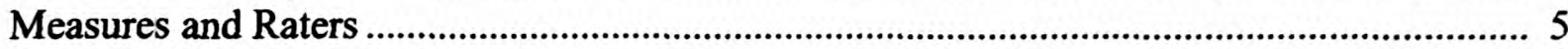

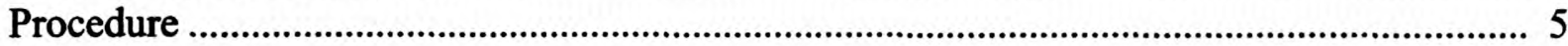

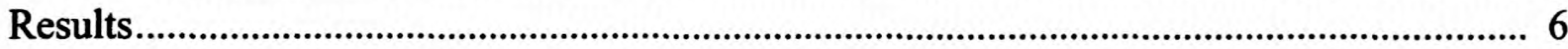

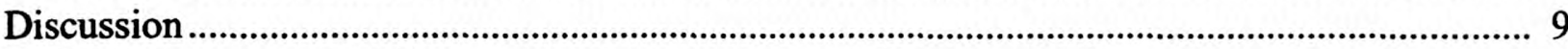

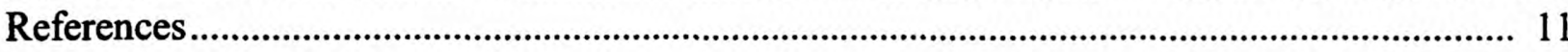

Appendix A Independent Evaluation Questionnaire ..................................................... A-1

Appendix B Radio Communications Checklist of Leader Awareness (RCCOLA) ............... B-1

Appendix C Future Expectations of Likely Leader Awareness (FELLA) Scale ..................... C-1

Appendix D Observation Frequency of RCCOLA Items by Two Raters

Over 42 Experimental Trials...................................................................... D-1

\section{List of Tables}

Table 1 Number of Items Classified by Item Authors and Independent Evaluators as Outstanding, Typical, and Poor SA

Table 2 Mean Percentage of Evaluator Agreement for 20 Items Representing

Each of Three Levels of SA.

Table 3 Mean Scores of Two Raters for Three SA Measures ............................................... 6

Table 4 Percentage of Interrater Agreement Across Items and Trials................................... 6

Table 5 Mean Scores of Three SA Measures and Mean Number of Radio

Transmissions for Three Squad Radio Conditions ............................................... 8

\section{List of Figures}

Figure 1 A comparison of the RCCOLA scores obtained from two raters across 42 trials (six trials for each of seven squad leaders) 